\section{Susceptibility of California Almond Cultivars to Aflatoxigenic Aspergillus}

\section{flavus}

\author{
Thomas M. Gradziel and Dechun Wang ${ }^{1}$ \\ Department of Pomology, University of Califomia, Davis, CA 95616
}

Additional index words. resistance, breeding, genetics, aflatoxin, Prunus dulcis, Aspergillus flavus

\begin{abstract}
Colonization and sporulation of aflatoxigenic Aspergillus flavus Link on intact and injured seed was evaluated for a selection of almond [Prunus dulcis (Mill.) D.A. Webb] cultivars. Barriers to fungal development were identified at the intact seedcoat and at the seed cotyledon tissue. The seedcoat barrier was expressed as a delay in fungal colonization for up to 3 days following the inoculation of intact seed. Seedcoat resistance was uniformly high for all cultivars tested. Cotyledon resistance, which was expressed as a lower rate of disease development was identified only in the cultivars Ne Plus Ultra, Ruby, and Carrion.
\end{abstract}

Nearly all North American almonds are produced in' California. Almond is an economically important crop due to the high value of the raw and processed product and because $\approx 60 \%$ of the $\$ 500$ million crop is exported, mainly to western Europe (Kesteret al., 1991).

Aflatoxins are an acutely toxic, carcinogenic, and immunosuppressive class of mycotoxin. Aflatoxin $\mathrm{B}$, is the most potent and carcinogenic naturally occurring substance known, causing liver damage to most domestic and experimental animals and humans (Diener et al., 1987). Aflatoxins $\mathrm{B}_{1}$ and $\mathrm{B}_{2}$ have been detected in California almond samples at very low frequencies (Fuller et al., 1977), but single contaminated kernels may contain high levels of toxin (Schade et al., 1975). The dosage of aflatoxin dangerous to humans is not known. A limit of 20 ppb has been established as the maximum permissible guideline level for aflatoxins in food commodities sold in the United States, whereas several western European countries have adopted permissible levels of $5 \mathrm{ppb}$ to zero tolerance (Stoloff, 1976).

Aflatoxin contamination in almond is due to the filamentous fungus Aspergillus flavus and, to a lesser extent, $A$. parasiticus Speare. Genetic resistance to these aflatoxigenic species has been identified in crops where the incidence of aflatoxin contamination is widespread, including maize (Zea mays L.) (Wallin, 1986; Zuber, 1977), cotton (Gossypium hirsutum L.) (Amalraj and Meshram, 1981), and groundnut or peanut (Arachis hypogaea

Received for publication 14 Aug. 1992. Accepted for publication 2July 1993. We gratefully acknowledgetheassistancefromNoel F.Sommerand Hamid Ahmadi. Support for this project was provided by a U.S. Dept. of Agriculture grant and by the Almond Board of California. The cost of publishing this paper was defrayed in part by the payment of page charges. Under postal regulations, this paper therefore must be herebymarked advertisement solely to indicate this fact.

'Current address: Dept. of Horticulture, Univ. of Michigan, East Lansing, MI 48824.
L.) (Mehan, 1989). Peanut breeding programs have identified barriers to fungal infection in the shell, seedcoat, and seed cotyledon (Vasudeva Rao et al., 1989). Shell characteristics have received considerable attention in almond breeding programs due to their role in insect resistance and meat: nut crack-out ratio. The seed's role in fungal infection and colonization has not been characterized. The purpose of this research was to assess seedcoat and seed embryo resistance to A. flavus in commercially planted California almond cultivars.

An aflatoxin $\mathrm{B}_{1}$ and $\mathrm{B}_{2}$ producing $A$. flavus isolate (\#76- 12) obtained from N.F. Sommer, Dept. of Pomology, Univ. of California, Davis, was used in all inoculations. Aspergillus flavus was cultured on a potato-dextrose-agar medium for 7 to 10 days by which time sporulaintact seed (right). tion had occurred. Sterile distilled water $(25$ $\mathrm{ml}$ ) with Tween-80 (Sigma, St. Louis) (twelve drops per liter) was then added to the flasks containing the fungal lawns. The mixture was agitated for $20 \mathrm{~min}$. The upper suspension was pipetted to a centrifuge tube and centrifuged at $5000 \times g$ for $5 \mathrm{~min}$. The supernatant was removed, and sterile distilled water without Tween- 80 was added to suspend spores. The spore suspension was then adjusted to a concentration of $2 \times 10^{6}$ spores $/ \mathrm{ml}$.

Fruit samples of each cultivar evaluated were collected from a San Joaquin Valley evaluation plot at the time of harvest. Additional samples were tested fro-m a Sacramento Valley evaluation plot for the cultivars Aldrich, Butte, Cannel, Fritz, Mission, Mono, Ne Plus Ultra, Nonpareil, Ruby, and Sonora. All samples were stored at $23 \mathrm{C}$ at $\approx 10 \%$ relative humidity for a minimum of 4 weeks to bring the sample moisture contents to uniform levels. To minimize damage to the seed and seedcoat, kernels were removed by hand from the fruit hull and shell.

Two inoculation treatments were used. In the first, uninjured kernels were inoculated. In the second, kernels were injured before inoculation. Artificial injury was achieved by slicing away a section of the seedcoat and $\approx 1 \mathrm{~mm}$ of underlying cotyledon tissue before inoculation (Fig. 1). Three replications of 20 kernels per treatment and per location were provided. Data from the two locations were pooled, as no location effect on cultivar susceptibility was detected.

Kernel samples were dated on trays in plastic containers. Moist paper towels were placed beneath the trays to maintain a high relative humidity. All samples were sprayinoculated using an atomizer until all exposed kernel surfaces were uniformly moist. Trays were loosely covered with plastic tops and incubated in darkness at 26C.

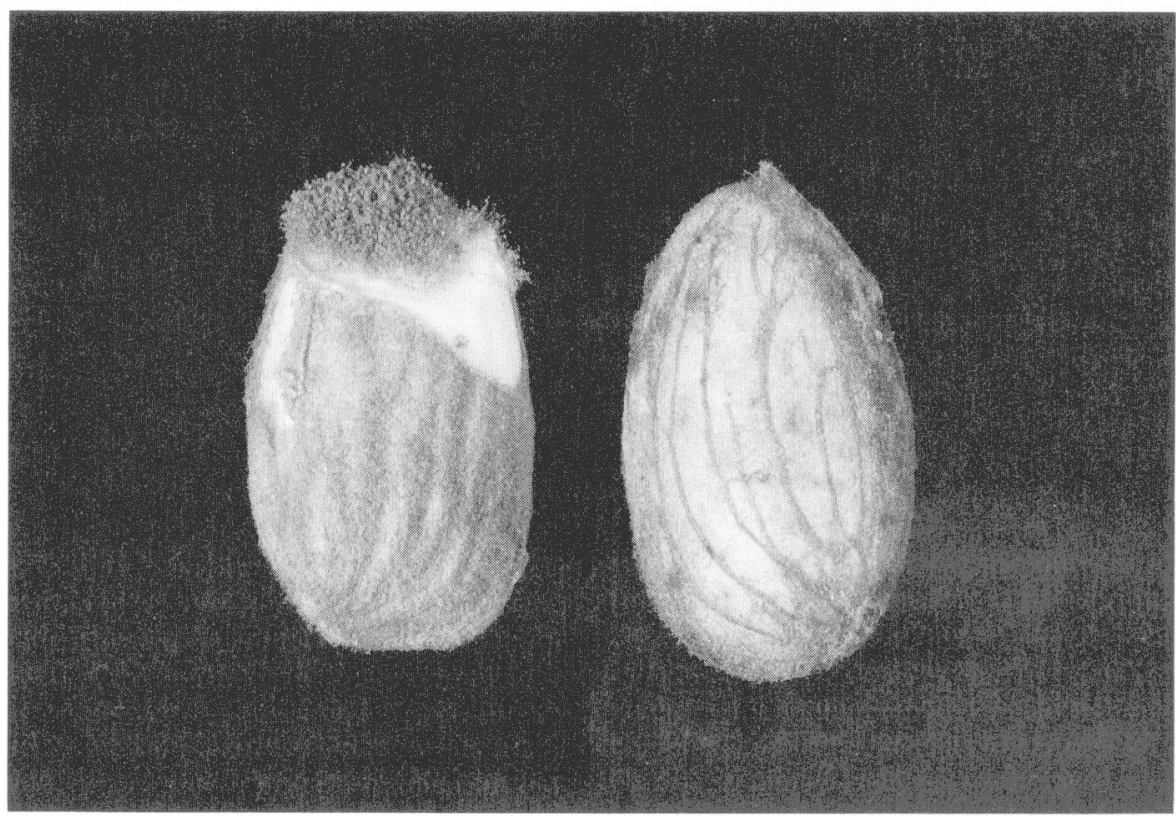

Fig. 1. 'Nonpareil' almond kernels 3 days after inoculation with Aspergillus flavus, showing extensive colonization on cotyledon tissue of artificially injured seed (left) and absence $\mathrm{f}$ visible colonization on 
The percentage of kernels showing fungal colonization was recorded for each treatment after 3,7, and 14 days. The degree of fungal sporulation on injured, infected kernels was rated on a 0 to 5 scale $(0=$ no sporulation; $5=$ very dense sporulation) at 3 and 7 days. Sporulation on the very susceptible 'LeGrand' was used as the standard for the very dense sporulation rating. Percentages data were analyzed by the SAS Duncan's multiple range test following arcsin transformation.

Colonization was absent on the third day following inoculation of uninjured kernels. The intact, mature seedcoat appears to be a barrier to fungal infection. This barrier may act by inhibiting the fungus directly as has been proposed for peanut (Dieckert and Dieckert, 1977), or it may act by restricting water uptake to the previously dried seed. Almond seed moisture contents necessary for fungal growth are $5 \%$ to $9 \%$ or higher (King et al., 1970; Phillips et al., 1976), a moisture content equivalent to that of a product in equilibrium with $70 \%$ relative humidity at 24C. Specific, factors associated with seedcoat resistance in peanut include low testa permeability, increased surface wax accumulation, uniform wax coating, thin testa with compact and tight cell structure, compact palisade-like layer, small hilum, presence of tannins and inhibitory compounds, and differences in amino acid composition (Vasudeva Rao et al., 1989).

Seven days after inoculation, considerable seed colonization and differences among cultivars were observed (Table 1). Significant differences among cultivars were also present 14 days after inoculation, differences that were very similar in ranking and relative magnitude to day 7 observations.' Ruby' and 'Ne Plus

Table 1. Comparison of colonization frequency means for samples of uninjured kernels of California almond cultivars at 7 and 14 days following inoculation with Aspergillus flavus., ${ }^{2, y}$

\begin{tabular}{lcc}
\hline & \multicolumn{2}{c}{ Seed colonization $(\%)$} \\
\cline { 2 - 3 } Cultivar & \multicolumn{2}{c}{ Day } \\
\cline { 2 - 3 } Jeffries & $56.7 \mathrm{ab}$ & $90.0 \mathrm{a}$ \\
LeGrand & $50.0 \mathrm{ab}$ & $90.0 \mathrm{a}$ \\
Mission & $58.3 \mathrm{a}$ & $86.7 \mathrm{a}$ \\
Rosetta & $37.5 \mathrm{ab}$ & $77.5 \mathrm{ab}$ \\
Woods Colony & $47.5 \mathrm{ab}$ & $75.0 \mathrm{ab}$ \\
Butte & $40.8 \mathrm{ab}$ & $73.3 \mathrm{ab}$ \\
Sauret \#2 & $41.7 \mathrm{ab}$ & $68.3 \mathrm{ab}$ \\
Carmel & $36.7 \mathrm{ab}$ & $65.8 \mathrm{ab}$ \\
Dottie Won & $43.3 \mathrm{ab}$ & $63.3 \mathrm{ab}$ \\
Nonpareil & $26.9 \mathrm{ab}$ & $62.5 \mathrm{ab}$ \\
Aldrich & $45.0 \mathrm{ab}$ & $60.0 \mathrm{ab}$ \\
Norman & $23.3 \mathrm{ab}$ & $56.7 \mathrm{ab}$ \\
Mono & $32.5 \mathrm{ab}$ & $56.7 \mathrm{ab}$ \\
Sonora & $22.5 \mathrm{ab}$ & $53.3 \mathrm{ab}$ \\
Padre & $31.7 \mathrm{ab}$ & $48.3 \mathrm{ab}$ \\
Price Cluster & $19.0 \mathrm{ab}$ & $46.7 \mathrm{ab}$ \\
Carrion & $20.0 \mathrm{ab}$ & $46.7 \mathrm{ab}$ \\
Fritz & $26.7 \mathrm{ab}$ & $45.0 \mathrm{ab}$ \\
Monterey & $21.7 \mathrm{ab}$ & $40.0 \mathrm{ab}$ \\
Ruby & $7.5 \mathrm{~b}$ & $34.2 \mathrm{~b}$ \\
Ne Plus Ultra & $8.3 \mathrm{~b}$ & $28.3 \mathrm{~b}$ \\
\hline No seeds &
\end{tabular}

${ }^{2}$ No seeds were colonized on day 3 .

yMean separation in columns by Duncan's multiple range test $(P \leq 0.05)$.

Table 2. Comparison of colonization frequency and sporulation rating means for samples of injured kernels of California almond cultivars at 3 and 7 days following inoculation with Aspergillus flavus. ${ }^{2}$

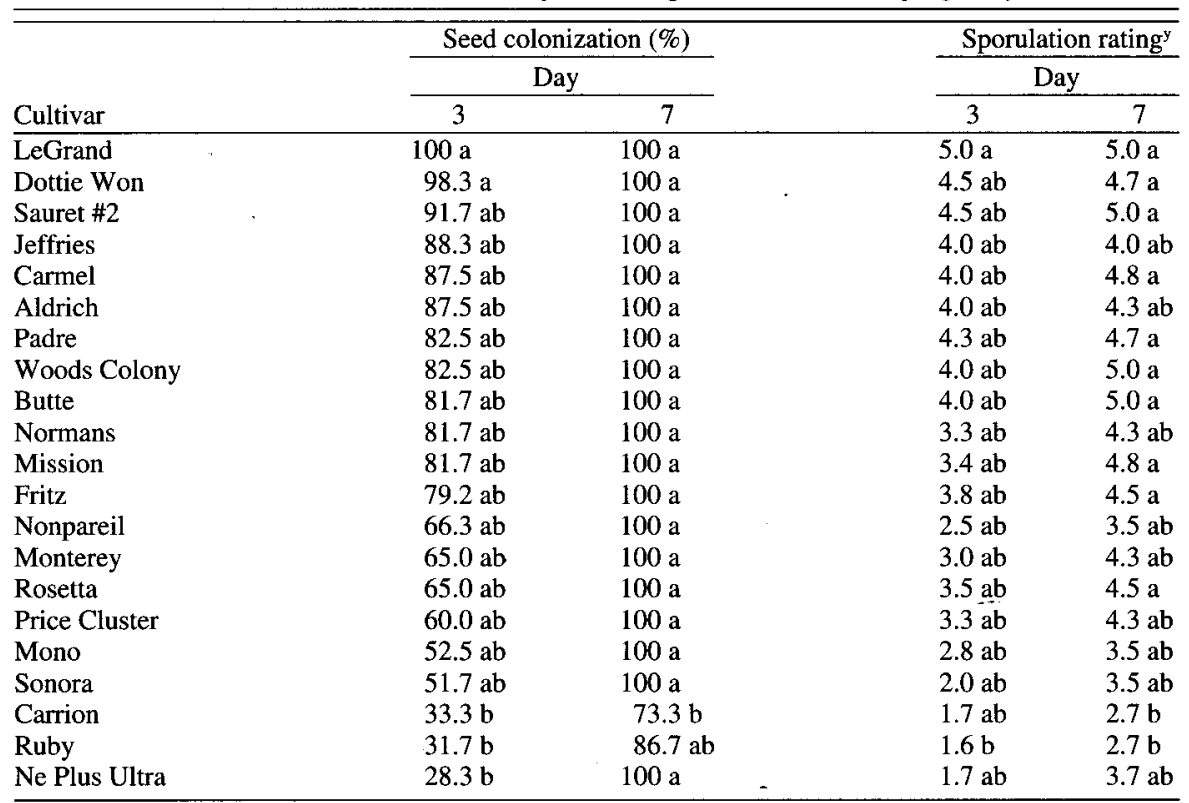

${ }^{2}$ Mean separation in columns by Duncan's multiple range test $(P \leq 0.05)$

'Sporulation rating: 0 (none) to 5 (very high).

Ultra' demonstrated the lowest levels of colonization; 'Jeffries', 'LeGrand', and 'Mission' showed some of the highest levels. However, differences were statistically significant only between the highest and lowest percentages. While a seedcoat barrier to water uptake might explain cultivar responses at 3 and 7 days following inoculation, the differences observed at 14 days are less likely the result of a hydration barrier since there was adequate time and moisture for rehydration. Differences in embryo tissue susceptibility to fungal colonization are therefore indicated.

Significant differences in susceptibility were observed among the various cultivars when cotyledon tissue was directly inoculated after artificial injury (Table 2). As with the uninjured inoculations, two susceptibility categories could be distinguished. The first category appears highly susceptible, as represented by the performance of 'LeGrand'. Cultivars showing $\approx 60 \%$ less colonization, including 'Ne Plus Ultra' and 'Ruby', makeup a second category with distinctly reduced susceptibility. 'Carrion' also performed well in inoculations of injured cotyledons, though less so in inoculations of those uninjured. Seed of the remaining cultivars were intermediate in their susceptibility. By day 7, samples of all cultivars, except 'Carrion' and 'Ruby', were fully colonized. All samples were fully colonized by day 14 .

Rankings of sporulation density are nearly identical to those based on colonization frequency. 'LeGrand' had the highest sporulation rating. 'Ne Plus Ultra', 'Ruby', and 'Carrion' received the lowest scores, although only certain differences were statistically significant. Cultivar differences were most distinct at 3 days following inoculation of injured seed, becoming less distinct after 7 days.

Our results suggest the existence of barriers to A. flavus development in the seedcoat and seed cotyledon composition. The seedcoat appeared to be an effective barrier to infection when intact. No differences in cultivar performance were observed for this response.

Improved levels of A. flavus resistance in the cotyledon tissue of 'Ruby', 'Ne Plus Ultra', and 'Carrion' are indicated by the relatively low colonization frequencies for injured and uninjured kernels and the low sporulation ratings. These barriers may prove to be useful sources of field resistance due to the low levels of natural infection (Schade et al., 1975) and the limited time period in which the kernel is susceptible under field conditions. The maturing kernel is vulnerable from the time of hull split, when the kernel is first exposed to fungal spores, to the stage where the water content in the desiccating seed has decreased below the level necessary for fungal growth. The kernels usually are sufficiently dehydrated by the time of harvest (Phillips et al., 1976). In peanut, where Aspergillus spp. epidemiology and in vitro colonization frequencies are similar to those in almond, in vitro colonization frequencies of $<15 \%$ are considered resistant (Mehan, 1989).

The uniform response observed in the remaining population was partially expected, as most of the cultivars presently planted have been shown by isozyme analysis (Hauagge et al., 1987) and analysis of the allelic distribution of the self-incompatibility(S) gene (Kester et al., 1994) to be closely related. Most are probably progeny of 'Nonpareil' and 'Mission'. Early work by King et al. (1970) failed to find evidence of an antibiotic effect in seed tissue from this population. 'Ne Plus Ultra' and 'Ruby' represent exceptions to this gene pool. 'Ne Plus Ultra' is an old cultivar, which, along with 'Nonpareil', 'IXL', and 'Peerless', was introduced to California in the late 1800s. Isozyme and self-incompatibility $(S)$ geno- 
type analysis support a parentage of 'Ruby' as being 'Ne Plus Ultra' and 'IXL'. 'Ruby' and 'Ne Plus Ultra' would thus represent a distinct germplasm from the 'Nonpareil' and 'Mission'-derived population. The origin of 'Carrion' is less clear, though isozyme data support 'Nonpareil' as one of the parents. 'LeGrand' is also distinct from 'Nonpareil' and 'Mission', as it possesses self-compatibility genes that were probably introgressed from peach/Prunus persica (Batsch) L.] (Kester et al., 1991).

While genetic variability for seed resistance to A. flavus appears low within the "Nonpareil' and 'Mission' -derived cultivars, the detection of increased levels of resistance outside this gene pool supports the possibility of additional resistance in other germplasm sources.

The epidemiology of A. flavus infection and aflatoxin formation is complex, and results from in vitro studies need to be carefully evaluated for field value. Kisyombe et al. (1985) obtained a good correlation between in vitro seed colonization experiments and field resistance in only one of the 14 peanut genotypes tested. Environmental factors showing a strong influence on infection and aflatoxin formation include temperature, time, and moisture (Diener et al., 1987). Insect damage, particularly by the Navel orangeworm [Amyelois transitella (Walk.)] has been strongly linked to A. flavus contamination in the field (Phillips et al., 1980). Insect damage to the seedcoat would obviate this protective barrier and may also vector fungal spores, while larval feeding might make the kernel microenvironment, particularly moisture content, more conducive to fungal growth (Phillips et al., 1976). Both the hull and the kernel have been shown by
Phillips et al. (1979) to harbor fungal species antagonistic to $A$. flavus growth. Consequently, genetic barriers to disease development must be used within the framework of a fully integrated pest and crop management program.

\section{Literature Cited}

Amalraj, S.F.A. and M.K, Meshram. 1981. Role of certain morphological characters in relation to boll rot resistance in Gossypium hirsutem L. Turnalba 31:381-383.

Dieckert, M.C. and J.W. Dieckert. 1977. Genetically determined structural parameters of the seed coat affecting the colonization of peanut seedsbyaflatoxin-producing Aspergilli. Annales de Technologies Agricole 26:353-366.

Diener, U. L., R.J. Cole, T.H. Sanders, G.A. Payne, L.S. Lee, and M.A. Klich. 1987. Epidemiology of aflatoxin formation by Aspergillus flavus. Ann. Rev. Phytopathol. 25:249-270.

Fuller,G.,W.W.Spooncer, A.D.King, Jr., J.Schade, and B. Mackey. 1977. Survey of aflatoxins in California tree nuts. J. Amer. Oil Chem. Sot. 54:231A-234A.

Hauagge, R., D.E.Kester,S.Arulsekar, D.E. Parfitt, and L. Liu. 1987. Isozyme variation among Californiaalmondcultivars:II.Cultivarchmacterization and origins. J. Amer. Soc. Hort. Sci. 112:693-698.

Kester,D.E.,T.M. Gradziel, andC. Grasselly. 1991. Almonds (R-anus), p. 701-758. In: J.N. Moore and J.R.Ballington,Jr.(eds.).Genetic resources of fruit and nut crops. Intl. Soc. Hort. Sci.

Kester,D.E.,T.M.Gradziel, and W.C. Micke. 1994. Identifying pollen incompatibility groups in California almond cultivars.J.Amer.Soc.Herr. Sei. 116:106-109.

King, A. D., Jr., M.J. Miller, and L.C. Eldridge. 1970. Almond harvesting, processing and $\mathrm{mi}-$ crobial flora.Appl. Microbiol. 20:208-2 14.

Kisyombe, C. Y., M.K. Beute, and G.A. Payne.
1985. Field evaluation of peanut genotypes for resistance to infection by Aspergillus parasiticus. Peanut Sci. 12:12-17.

Mehan,V.K. 1989. Screening for resistance to seed invasion by Aspergillus flavus and to aflatoxin production, p. 323-334. In: D. McDonald and V.K. Mehan (eds.). Proceedings of the international workshop on aflatoxin contamination of groundnut.Intl.CropRes.Inst.for the Semi-arid Tropics,Patancheru, India.

Phillips, D.J., B. Mackey, W.R. Ellis, and T.N. Hansen. 1979. Occurrence and interaction of Aspergillus flavus with almond. Phytopathology 69:829-831.

Phillips, D.J., S.L. Purcell, and G.I. Stanley. 1980 Aflatoxins in almond. U.S. Dept. of Agr. Sci. and Educ. Admin., ARM-W-20, Fresno, Calif.

Phillips, D.J.,M.Uota,D.Monticello, and C. Curtis. 1976. Colonization of almond by Aspergillus flavus. J. Amer. Soc. Hort. Sci. 100:19-23.

Schade, J.E., R. McGreevey, A.D. King, Jr., B. Mackey, and G. Fuller. 1975. Incidence of aflatoxin in California almonds. Appl. Microbiol. 29:48-53.

Stoloff,L.1976. Incidence, distribution, and disposition of products containing aflatoxin. Proc. Amer. Phytopathol Soc. 3:15-172.

Vasudeva Rae, M.J., S.N. Nigam, V.K. Mehan, and D. McDonald. 1989. Aspergillus flavus resistance breeding in groundnut: Progress made at ICRISAT Center, p. 345-354. In: D. McDonald andV.K.Meharr(eds.).Proceedingsofthe international workshop on aflatoxin contamination of groundnut. Intl. Crop Res. Inst. for the Semiarid Tropics,Patancheru, India.

Wallin, J.R. 1986. Production of aflatoxin in woundedand whole maize kernels by Aspergillus flavus. Plant Dis. 429-430.

Zuber, M.S. 1977. Influence of plant genetics on toxin production in corn, p. 173-179. In: J.V. Rodricks,C.W.Hesseltine, and M.A. Mehlman (eds.).Mycotoxinsinhuman and animal health. PathotoxPublishers,ParkForestSouth, Ill. 